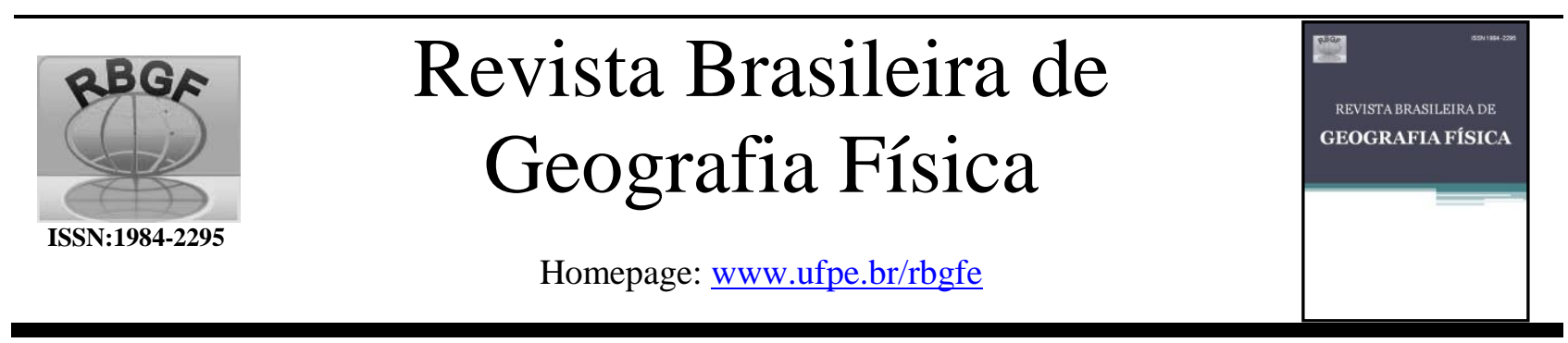

\title{
Análise do processo de co-combustão da biomassa, através da influência da umidade do cavaco na emissão de contaminantes atmosféricos, eficiência energética e geração de cinzas
}

\author{
Roger Francisco Ferreira de Campos $^{1}$ Leandro Della Rosa ${ }^{2}$ Tiago Borga ${ }^{3}$
}

${ }^{1}$ Professor da Universidade Alto Vale do Rio do Peixe (UNIARP) e Mestrando pelo programa de pós-graduação em Ciências Ambientais da Universidade Estadual de Santa Cataria (UDESC) - roger@uiarp.edu.br, ${ }^{2}$ Engenheiro Ambiental pela Universidade Alto Vale do Rio do Peixe UNIARP - leandro.dallarosa@adami.com.br, ${ }^{3}$ Professor da Universidade Alto Vale do Rio do Peixe (UNIARP) e Mestrando em Desenvolvimento e Sociedade pela da Universidade Alto Vale do Rio do Peixe - UNIARP- tiagoborga@ gmail.com,

Artigo recebido em 11/04/2017 e aceito em 04/07/2017

\begin{abstract}
R E S U M O
A poluição ambiental e atmosférica decorre de uma junção de fatores, como o crescimento e as concentrações populacionais e industriais. As caldeiras são equipamentos destinados à produção de vapor sob pressão superior à atmosférica, que utiliza a biomassa como fonte geradora de energia, emitindo uma quantidade significativa de contaminantes atmosféricos. Sabendo que o maior impacto ambiental produzido pelas caldeiras é a emissão de gases, materiais particulados e a geração de hidrocarbonetos, objetivou-se quantificar a variação de emissão de gases poluentes $\left(\mathrm{CO}_{2}, \mathrm{CO}, \mathrm{O}_{2}\right)$, eficiência de queima e geração de cinzas em função da umidade do combustível na empresa Adami S/A. $\mathrm{O}$ estudo foi realizado in loco em uma caldeira aquatubular, onde se analisou a emissão dos gases durante a queima da biomassa (Cavaco de Pinus sp.) com 52\%, 40\%, 30\% e 25\% de umidade. A partir das análises identificou-se que alta emissão de gás contaminante se dá devido principalmente pela umidade do combustível entre outros fatores. Apesar de as emissões que foram medidas na caldeira da empresa Adami S/A estarem todas dentro dos parâmetros legais, deve-se tentar reduzir a quantidade de monóxido de carbono emitido, devido ao seu impacto no meio ambiente. Assim, esse trabalho visa apresentar a interação da umidade da biomassa de Pinus sp. com a emissão de gases poluentes, pois são poucos os estudos relacionando a queima de biomassa com a emissão de gases.
\end{abstract}

Palavras-chave: caldeira. biomassa. poluição atmosférica. gases poluentes. qualidade do ar.

\section{Analysis of the biomass co-combustion process, through the influence of chip humidity on the emission of atmospheric contaminants, energy efficiency and ash generation}

\begin{abstract}
A B S T R A C T
Environmental and atmospheric pollution stems from a combination of factors such as population and industrial growth and concentrations. Boilers are equipment for the production of steam under pressure above atmospheric, which uses biomass as a steam source, emitting a significant amount of atmospheric contaminants. Knowing that the greatest environmental impact produced by the boilers is the emission of gases, particulates and the generation of hydrocarbons, the objective was to quantify the emission of pollutant gases $\left(\mathrm{CO}_{2}, \mathrm{CO}, \mathrm{O}_{2}\right)$, burning efficiency and ash generation in Function of the fuel in the company Adami S/A. The study was carried out in loco in an aquatubular boiler, where the emission of the gases during the burning of the biomass (Cavaco de Pinus sp.) with 52\%, 40\%, 30\% and 25\% of humidity was analyzed. From the analyzes it was identified that high emission of contaminating gas is mainly due to the humidity of the fuel among other factors. Although the emissions that were measured in the boiler of the Adami S/A company are all within the legal parameters, one should try to reduce the amount of carbon monoxide emitted due to its impact on the environment. Thus, this work aims to present the interaction of the biomass moisture of Pinus sp. with the emission of pollutant gases, since few studies relate the burning of biomass with the emission of gases.
\end{abstract}

Keywords: boiler. biomass. air pollution. gaseous pollutants. air quality. 


\section{Introdução}

A poluição ambiental pode ser considerada como um processo de degradação do ambiente devido às atividades que direta ou indiretamente afetem a saúde, a segurança e o bem estar da população. Que decorre de uma junção de fatores, como o crescimento e a concentração populacional, industrial e econômica, assim como dos hábitos da população e da falta de controle destes fatores (Braga et al., 2010).

A poluição atmosférica não é um processo recente e de inteira responsabilidade do homem, pois desde milhares de anos atrás a própria natureza participa ativamente deste processo através do lançamento de gases e materiais particulados originados de atividades vulcânicas e tempestades, dentre outras fontes naturais de poluentes (Mano et al., 2010). No entanto, a atividade humana intensifica este tipo de poluição, através do lançamento contínuo de grandes quantidades de substâncias heterogenias (Oliveira, 1997, Arbex et al., 2004). Com a industrialização mundial, cresce cada vez mais as preocupações com o meio ambiente, pois as indústrias utilizam dos recursos naturais para os processos de produção (Mano et al., 2010).

As caldeiras, também chamadas de geradores de vapor são equipamentos que utilizam alguma fonte de energia, destinados à produção de vapor sob pressão superior à atmosférica. $\mathrm{O}$ vapor que é produzido por esses equipamentos é largamente utilizado para movimentar máquinas térmicas, além de ser fonte de calor para processos industriais. As caldeiras transferem a energia armazenada nas fontes de combustíveis para a água e, em seguida, para a aplicação final (Brizo, 2004). As reações de combustão estão presentes em muitos processos industriais e também na geração de energia (Sales et al., 2005; Padilha et la., 2005). Segundo Francisco (2012), 85\% da energia que se é utilizada no processo de produção (geração de vapor) provém da combustão, estando presente na maioria dos setores como um processo estratégico para a economia de produção dos países. Os processos industriais que exigem a queima de combustíveis são a secagem de materiais cerâmicos, moldagem de polímeros, fundição de metais, tratamentos térmicos de peças metálicas, produção e moldagem de vidro, manufatura de alimentos, entre outros (Freitas, 2013).

A grande vantagem da utilização da biomassa na queima em caldeiras em relação a outras fontes de energia renovável é a possibilidade de controle da geração de energia de acordo com as necessidades. O uso da biomassa para a produção de calor é vantajosa se comparada ao uso de combustíveis fósseis, com exceção do gás natural (Offermann et al., 2011).

A biomassa é um material orgânico que se origina a partir das plantas, sendo a madeira seu principal componente (Angelis-Dimakis et al., 2011). Quimicamente é composto por holocelulose, lignina, extrativos, cinzas e matéria inorgânica (Blasi, 2005). Para Wander (2001) e Brand et al. (2014a) a utilização de biomassa para produção de calor é um alternativa sustentável para resolver o problema da indústria de base florestal, pois a utilização do Pinus sp. como biomassa é uma fonte para destinação desse resíduos. Segundo Baretta et al. (2010) a utilização de biomassa de base florestal, reduz $18 \%$ o preparo do solo após colheita, pela utilização da casca e da desgalhada, como também as cinzas geradas no processo de geração energética pode ser utilizadas como fonte nutricional para os solos.

De acordo com a Companhia Ambiental Do Estado De São Paulo - CETESB (2015) a queima de biomassa em caldeira está associada ao processo de obtenção de energia e calor, como para diminuir os possíveis danos ambientais de destinação dos resíduos sólidos. Devido às essas questões existe um grande interesse das indústrias em ampliarem suas margens de lucro com o investimento em projetos sustentáveis que apresentem técnicas confiáveis e consolidadas, motivando assim o estudo da aplicabilidade dessas tecnologias disponíveis no mercado, além do retorno financeiro que as mesmas podem proporcionar. Desta forma, se torna cada vez mais importante o desenvolvimento de metodologias de identificação de soluções para reduzir as perdas energéticas e de eficiência, bem como formas de reduzir a emissão de gases poluentes provenientes da queima dos combustíveis (Salum, 2011).

Sabendo que um dos impactos ambientais produzidos pelas caldeiras e a emissão de gases, questiona-se, se a partir do monitoramento contínuo das emissões é possível avaliar sua eficiência no processo de combustão, bem como quantificar os poluentes emitidos. Buscando aperfeiçoar as relações de queima e umidade para um melhor aproveitamento de combustível e a redução de emissões gasosas. Portanto, a pesquisa pauta-se no objetivo geral de quantificar a variação de emissão de gases em função da umidade da biomassa, com a perspectiva de analisar a umidade ideal da biomassa, buscando uma maior eficiência energética e eficiência ambiental.

\section{Metodologia}


As analises de emissões de gases foram realizadas no município de Caçador $/ \mathrm{SC}$, a $400 \mathrm{~km}$ da capital Florianópolis, onde fica localizada a empresa Adami S/A, na Rodovia SC-302, km 6,5, $\mathrm{s} / \mathrm{n}$, linha castelhano, com as coordenadas geográficas $26^{\circ} 48^{\prime} 40^{\prime \prime}$ S. $26^{\circ} 48^{\prime} 18,51^{\prime \prime}$ sendo uma das maiores fabricas de papel da região, conforme Figura 1.

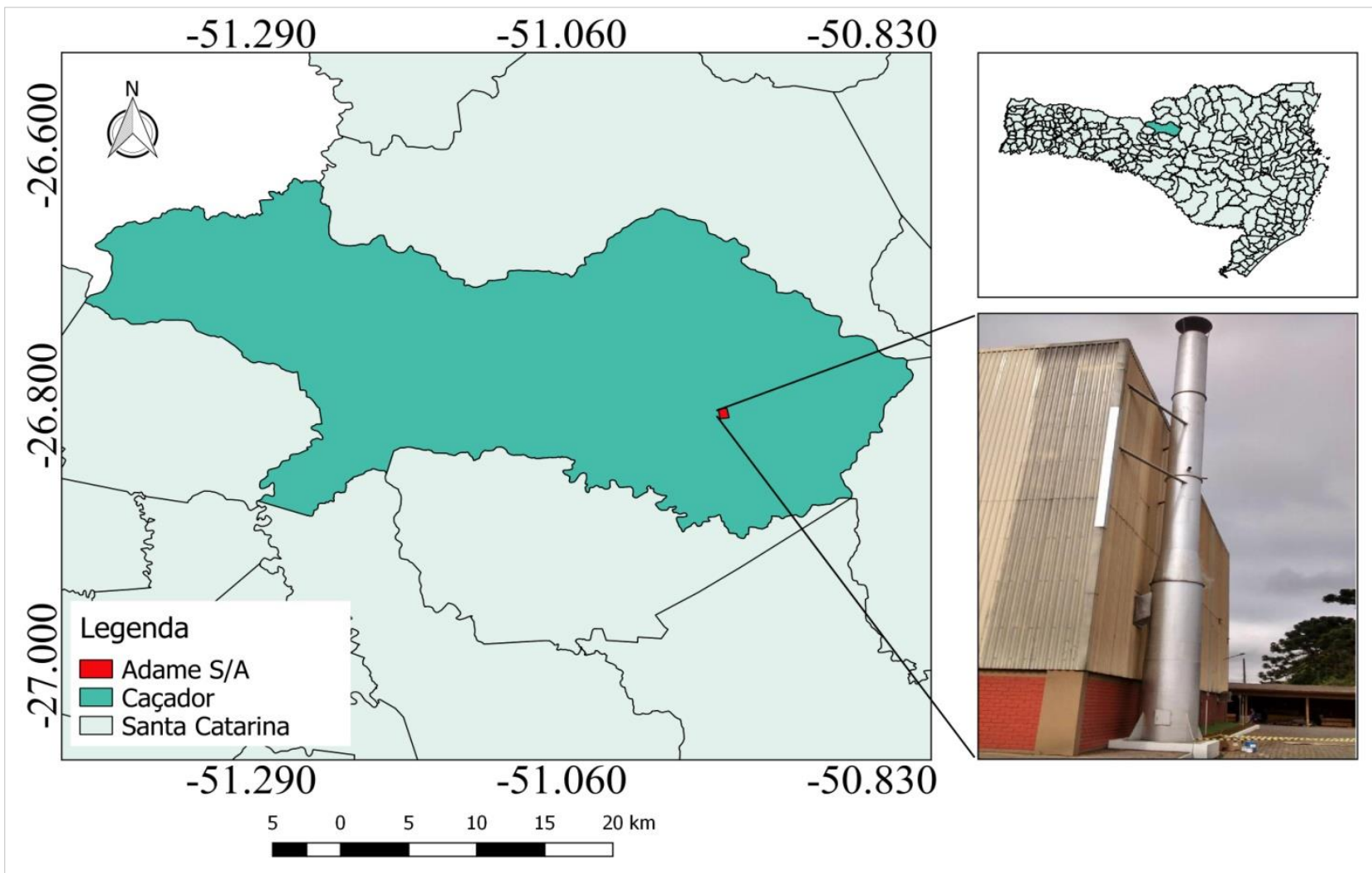

Figura 1. Localização da área do estudo, Caçador, Santa Catarina;

O estudo foi realizado in loco em uma caldeira aquatubular com pressão de $21 \mathrm{kgf}$ e capacidade de geração de vapor de $20.000 \mathrm{~kg}$.hora ${ }^{-}$ 1. Com capacidade de queimar até $25.000 \mathrm{~kg} \cdot$ hora $^{-1}$ de biomassa e carga térmica de $8,68 \mathrm{mw}$. A mesma é de modulação automática comandada por inversores de frequência ligada nos ventiladores de ar primário, ar secundário e exaustor de tiragem, e tem como receptor de fuligem filtros multiciclones.

A empresa do estudo possui como sistema de geração de energia térmica as caldeiras, também chamadas de geradores de vapor que são equipamentos que utilizam alguma fonte de energia, e são destinados à produção de vapor sob pressão superior à atmosférica. $\mathrm{O}$ vapor que é produzido por esses equipamentos é largamente utilizado para movimentar máquinas térmicas, além de ser fonte de calor para processos industriais. Entre as etapas produtivas desde o recebimento da matéria prima, desagregação, formação do papel existe uma etapa denominada secagem do papel, é nessa etapa que é utilizado o vapor gerado na caldeira, toda água que não foi extraída da formação do papel por meio físico e hidráulico. Posteriormente é retirada do papel por meio de transferência de calor "condução térmica", onde esse vapor entra em contato com cilindros secadores, e por sua vez é transferido para a folha de papel onde a umidade é evaporada por troca de calor entre as folhas e os secadores e o meio.

O principal combustível utilizado nas caldeiras da empresa é a biomassa de Pinus $s p$. picado, que é composta por $30 \%$ de serragem; $10 \%$ de casca; e $60 \%$ fibra de madeira. A empresa conta com a utilização de uma biomassa padrão de $52 \%$, recebendo cerca de \pm 12.000 toneladas mês de biomassa, através de 23 fornecedores de toda região. Essas cargas de biomassa são pesadas e posteriormente retiradas amostra para analise, no laboratório químico da própria da empresa. Posteriormente, é acondicionada em silos, após isso a biomassa é transportada por esteiras e roscas transportadoras até a chegada na caldeira quando é iniciada a queima da mesma para ser transformada em energia térmica.

Esse funcionamento pode ser visto no fluxograma de ar e gases disposto na Figura 2. 


\section{FLUXOGRAMA DE AR E GASES}

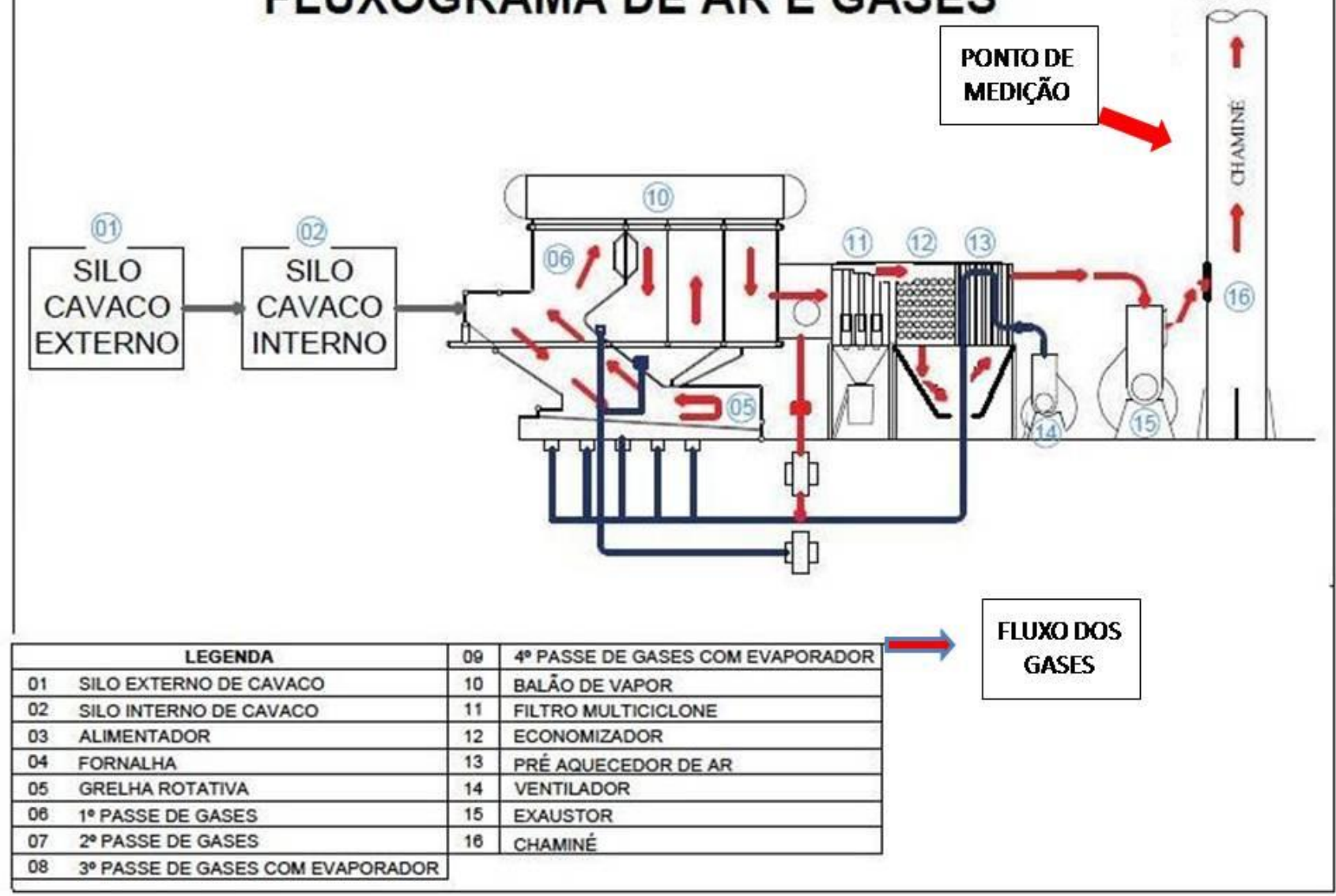

Figura 2. Fluxograma de ar e gases da caldeira estudada;

Para as variáveis de análise da biomassa foi utilizada uma biomassa padrão de $52 \%$ de umidade para apresentar o atual cenário da empresa, como também três biomassa com diferentes umidades $(40 \%, 30 \%$ e $25 \%)$ para analisar a interação da umidade com a biomassa, sendo que a umidade da biomassa foi determinada pelo equipamento analisador de umidade da marca MOGmobil, seguindo os parâmetros da NBR 14929/2003, onde o Teor de Umidade do Cavaco (TUC) corresponde à relação entre a massa da água nela contida e a massa da madeira seca. A Equação 1. fornece a relação para determinação do teor de umidade da madeira (TU), onde $\mathrm{M}_{1}$ é a massa inicial da madeira (em gramas) e $\mathrm{M}_{2}$ é a massa de madeira seca (em gramas).

$$
\operatorname{TUC}(\%)=\frac{\mathrm{M} 1-\mathrm{M} 2}{\mathrm{M} 1} \times 100
$$

Para a análise da eficiência da biomassa foi utilizado 2 toneladas de biomassa para cada lote de umidade, totalizando 100 toneladas de biomassa combinadas. Após a determinação da umidade na biomassa, os diferentes lotes de biomassa foram submetidos a queima na caldeira. Sendo que a medição de emissão de gases foi realizada na fonte geradora de vapor, enquadrado nas fontes estacionárias de emissão de gases, para esse análise foi utilizado um aparelho Tempest-50 da marca Telegan, devidamente calibrado.

Os parâmetros estabelecidos para análise foram o Dióxido de Carbono $\left(\mathrm{CO}_{2}\right)$, Monóxido de Carbono (CO), Oxigênio $\left(\mathrm{O}_{2}\right)$, além de eficiência de queima e geração de cinzas. A emissão de gases foi realizada a cada 5 minutos no período de uma hora, totalizando a queima da biomassa. Os dados foram submetidos à análise de variância e as médias comparadas pelo teste de Tukey a $5 \%$ de probabilidade, com auxílio do programa ASSISTAT versão 7.7 beta (Silva e Azevedo, 2009).

O presente estudo tem como base cumprir o estabelecido pela Resolução CONAMA 436/2011, que estabelece o limite de lançamento de poluentes atmosféricos gerados no processo de combustão externa de derivados da madeira, regulamentado pelo ministério do meio ambiente sobre a lei $\mathrm{n}^{\circ}$ 6.938, de 31 de agosto de 1981 (Brasil, 2011). 


\section{Resultados}

A Tabela 1. apresenta os valores pontuais e as médias dos valores de dióxido de carbono para os quatro lotes de biomassa com diferentes tipos de umidade. ${ }^{(1)}$

Tabela 1. Geração de dióxido de carbono durante a queima de diferentes umidades;

\begin{tabular}{cccccc}
\hline \multirow{2}{*}{ MINUTO } & \multicolumn{4}{c}{ Emissão de CO $\mathbf{C O}_{2} /$ Umidade } & \multirow{2}{*}{ MÉDIA } \\
\cline { 2 - 4 } & $\mathbf{5 2 \%}$ & $\mathbf{4 0 \%}$ & $\mathbf{3 0 \%}$ & $\mathbf{2 5 \%}$ & \\
\hline $\mathbf{1}$ & 14,10 & 13,60 & 10,60 & 9,60 & $\mathbf{1 1 , 9 8} \mathbf{A}$ \\
$\mathbf{5}$ & 14,60 & 13,40 & 10,40 & 9,50 & $\mathbf{1 1 , 9 8} \mathbf{A}$ \\
$\mathbf{1 0}$ & 14,70 & 13,30 & 10,20 & 9,20 & $\mathbf{1 1 , 8 5} \mathbf{A}$ \\
$\mathbf{1 5}$ & 16,20 & 13,50 & 10,40 & 9,40 & $\mathbf{1 2 , 3 8} \mathbf{A}$ \\
$\mathbf{2 0}$ & 15,60 & 13,60 & 10,30 & 9,10 & $\mathbf{1 2 , 1 5} \mathbf{A}$ \\
$\mathbf{2 5}$ & 14,60 & 13,10 & 10,60 & 9,40 & $\mathbf{1 1 , 9 3} \mathbf{A}$ \\
$\mathbf{3 0}$ & 14,40 & 13,00 & 10,30 & 9,20 & $\mathbf{1 1 , 7 3} \mathbf{A}$ \\
$\mathbf{3 5}$ & 14,10 & 13,10 & 10,20 & 8,60 & $\mathbf{1 1 , 5 0} \mathbf{A}$ \\
$\mathbf{4 0}$ & 14,50 & 13,50 & 10,60 & 9,30 & $\mathbf{1 1 , 9 8} \mathbf{A}$ \\
$\mathbf{4 5}$ & 14,30 & 13,40 & 10,40 & 9,20 & $\mathbf{1 1 , 8 3} \mathbf{A}$ \\
$\mathbf{5 0}$ & 14,60 & 13,60 & 10,10 & 9,40 & $\mathbf{1 1 , 9 3} \mathbf{A}$ \\
$\mathbf{5 5}$ & 14,40 & 13,30 & 10,40 & 9,30 & $\mathbf{1 1 , 8 5} \mathbf{A}$ \\
$\mathbf{6 0}$ & 14,10 & 13,40 & 10,50 & 9,60 & $\mathbf{1 1 , 9 0} \mathbf{A}$ \\
& -------------------------- & \\
\hline MÉDIA & $\mathbf{1 4 , 6 3} \mathbf{a}$ & $\mathbf{1 3 , 3 7} \mathbf{b}$ & $\mathbf{1 0 , 3 8} \mathbf{c}$ & $\mathbf{9 , 2 9} \mathbf{d}$ & $\mathbf{1 1 , 9 3}$ \\
\hline Variância & 0,04 & 0,04 & 0,03 & 0,06 & 0,05 \\
Desvio padrão & 0,61 & 0,20 & 0,16 & 0,26 & 0,21 \\
Erro padrão & 0,18 & 0,06 & 0,05 & 0,07 & 0,06 \\
\hline
\end{tabular}

(1) Valores seguidos pela mesma letra, minúscula na linha e maiúscula na coluna, não diferem significativamente entre si de acordo com o teste de Tukey $(\mathrm{p} \leq 0,05)$.

A Tabela 2. apresenta os valores pontais de emissão de monóxido de carbono e as médias para quatro lotes de biomassa com diferentes tipos de umidade. ${ }^{(1)}$

Tabela 2. Geração de monóxido de carbono durante a queima de diferentes umidades;

\begin{tabular}{|c|c|c|c|c|c|}
\hline \multirow{2}{*}{ MINUTO } & \multicolumn{4}{|c|}{ Emissão de CO/Umidade } & \multirow{2}{*}{ MÉDIA } \\
\hline & $52 \%$ & $40 \%$ & $\mathbf{3 0 \%}$ & $25 \%$ & \\
\hline 1 & 820,00 & 724,00 & 654,00 & 450,00 & $662,00 \mathrm{~A}$ \\
\hline 5 & 810,00 & 790,00 & 632,00 & 423,00 & $663,75 \mathrm{~A}$ \\
\hline 10 & 825,00 & 745,00 & 622,00 & 412,00 & $651,00 \mathrm{~A}$ \\
\hline 15 & 790,00 & 710,00 & 644,00 & 421,00 & $641,25 \mathrm{~A}$ \\
\hline 20 & 730,00 & 700,00 & 632,00 & 354,00 & $604,00 \mathrm{~A}$ \\
\hline 25 & 750,00 & 710,00 & 648,00 & 388,00 & $624,00 \mathrm{~A}$ \\
\hline 30 & 774,00 & 725,00 & 654,00 & 349,00 & $625,50 \mathrm{~A}$ \\
\hline 35 & 712,00 & 729,00 & 670,00 & 380,00 & $622,75 \mathrm{~A}$ \\
\hline 40 & 723,00 & 712,00 & 665,00 & 391,00 & $622,75 \mathrm{~A}$ \\
\hline 45 & 820,00 & 774,00 & 640,00 & 357,00 & $647,75 \mathrm{~A}$ \\
\hline 50 & 816,00 & 790,00 & 625,00 & 401,00 & $658,00 \mathrm{~A}$ \\
\hline 55 & 810,00 & 778,00 & 623,00 & 354,00 & $641,25 \mathrm{~A}$ \\
\hline 60 & 832,00 & 746,00 & 645,00 & 368,00 & $647,75 \mathrm{~A}$ \\
\hline MÉDIA* & 785,54 a & $741,00 \mathrm{~b}$ & $642,62 \mathrm{c}$ & $388,31 \mathrm{~d}$ & 641,25 \\
\hline Variância & 1790,60 & 1197,02 & 262,99 & 1065,63 & 353,49 \\
\hline Desvio padrão & 42,85 & 32,19 & 15,54 & 31,88 & 018,88 \\
\hline Erro padrão & 12,22 & 9,70 & 4,68 & 9,44 & 005,43 \\
\hline
\end{tabular}


(1) Valores seguidos pela mesma letra, minúscula na linha e maiúscula na coluna, não diferem significativamente entre si de acordo com o teste de Tukey $(\mathrm{p} \leq 0,05)$.

A Tabela 3. apresenta os valores pontais de emissão de oxigênio e as médias para quatro lotes de biomassa com diferentes tipos de umidade. ${ }^{(1)}$

Tabela 3. Geração de oxigênio durante a queima de diferentes umidades;

\begin{tabular}{|c|c|c|c|c|c|}
\hline \multirow{2}{*}{ MINUTO } & \multicolumn{4}{|c|}{ Emissão de $\mathrm{O}_{2} /$ Umidade } & \multirow{2}{*}{ MÉDIA* } \\
\hline & $52 \%$ & $40 \%$ & $30 \%$ & $25 \%$ & \\
\hline 1 & 6,50 & 7,00 & 10,00 & 11,00 & $8,63 \mathrm{~A}$ \\
\hline 5 & 6,00 & 7,20 & 10,20 & 11,10 & $8,63 \mathrm{~A}$ \\
\hline 10 & 5,90 & 7,30 & 10,40 & 11,40 & $8,75 \mathrm{~A}$ \\
\hline 15 & 4,40 & 7,10 & 10,20 & 11,20 & $8,23 \mathrm{~A}$ \\
\hline 20 & 5,00 & 7,00 & 10,30 & 11,50 & $8,45 \mathrm{~A}$ \\
\hline 25 & 6,00 & 7,50 & 10,00 & 11,20 & $8,68 \mathrm{~A}$ \\
\hline 30 & 6,20 & 7,60 & 10,30 & 11,40 & $\mathbf{8 , 8 8} \mathrm{A}$ \\
\hline 35 & 6,50 & 7,50 & 10,40 & 12,00 & $9,10 \mathrm{~A}$ \\
\hline 40 & 6,10 & 7,10 & 10,00 & 11,30 & $8,63 \mathrm{~A}$ \\
\hline 45 & 6,30 & 7,20 & 10,20 & 11,40 & $8,78 \mathrm{~A}$ \\
\hline 50 & 6,00 & 7,00 & 10,50 & 11,20 & $8,68 \mathrm{~A}$ \\
\hline 55 & 6,20 & 7,30 & 10,20 & 11,30 & $8,75 \mathrm{~A}$ \\
\hline \multirow[t]{2}{*}{60} & 6,50 & 7,20 & 10,10 & 11,00 & $8,70 \mathrm{~A}$ \\
\hline & & & $\%$------- & & \\
\hline MÉDIA* & $5,97 \mathrm{~d}$ & $7,30 \mathrm{c}$ & 10,22 b & 11,31 a & 8,68 \\
\hline Variância & 0,38 & 0,04 & 0,03 & 0,06 & 0,05 \\
\hline Desvio padrão & 0,61 & 0,20 & 0,16 & 0,26 & 0,21 \\
\hline Erro padrão & 0,18 & 0,06 & 0,05 & 0,07 & 0,06 \\
\hline
\end{tabular}

(1) Valores seguidos pela mesma letra, minúscula na linha e maiúscula na coluna, não diferem significativamente entre si de acordo com o teste de Tukey $(\mathrm{p} \leq 0,05)$.

A Tabela 4. apresenta os valores de eficiência energética da queima e as médias para quatro lotes de biomassa com diferentes tipos de umidade. ${ }^{(1)}$

Tabela 4. Eficiência da queima energética com diferentes umidades;

\begin{tabular}{|c|c|c|c|c|c|}
\hline \multirow{2}{*}{ MINUTO } & \multicolumn{4}{|c|}{ EFICIÊNCIA DE QUEIMA } & \multirow{2}{*}{ MÉDIA } \\
\hline & $52 \%$ & $40 \%$ & $30 \%$ & $25 \%$ & \\
\hline 1 & 74,00 & 77,00 & 82,00 & 88,00 & $80,25 \mathrm{~A}$ \\
\hline 5 & 74,00 & 77,10 & 82,80 & 87,60 & $80,38 \mathrm{~A}$ \\
\hline 10 & 73,80 & 77,00 & 83,00 & 89,00 & $80,70 \mathrm{~A}$ \\
\hline 15 & 72,40 & 77,00 & 82,40 & 88,50 & 80,08 A \\
\hline 20 & 72,00 & 76,00 & 81,00 & 89,40 & $79,60 \mathrm{~A}$ \\
\hline 25 & 74,20 & 78,00 & 81,20 & 89,20 & $80,65 \mathrm{~A}$ \\
\hline 30 & 72,30 & 78,40 & 82,40 & 88,20 & $80,33 \mathrm{~A}$ \\
\hline 35 & 72,10 & 77,90 & 83,00 & 89,30 & $80,58 \mathrm{~A}$ \\
\hline 40 & 71,50 & 77,20 & 81,40 & 89,80 & 79,98 A \\
\hline 45 & 75,00 & 78,50 & 84,00 & 90,10 & $81,90 \mathrm{~A}$ \\
\hline 50 & 72,50 & 78,00 & 83,10 & 90,00 & $80,90 \mathrm{~A}$ \\
\hline 55 & 72,20 & 77,90 & 82,40 & 89,70 & $80,55 \mathrm{~A}$ \\
\hline 60 & 71,00 & 79,20 & 83,10 & 89,50 & $80,70 \mathrm{~A}$ \\
\hline MÉDIA* & 72,85 a & $77,63 \mathrm{~b}$ & $82,45 \mathrm{c}$ & $89,10 \mathrm{~d}$ & 80,47 \\
\hline Variância & 1,262 & 0,535 & 0,772 & 0,675 & 0,323 \\
\hline Desvio padrão & 1,210 & 0,844 & 0,864 & 0,796 & 0,586 \\
\hline Erro padrão & 0,324 & 0,211 & 0,254 & 0,237 & 0,164 \\
\hline
\end{tabular}


(1) Valores seguidos pela mesma letra, minúscula na linha e maiúscula na coluna, não diferem significativamente entre si de acordo com o teste de Tukey $(\mathrm{p} \leq 0,05)$.

A Tabela 5. apresenta os volumes de cinza

biomassa em função de sua umidade e eficiência em $\mathrm{m}^{3}$ gerados para cada lote com 25 toneladas de energética.

Tabela 5. Volume de cinza para cada 25 toneladas de biomassa queimada;

\begin{tabular}{ccc}
\hline Umidade da biomassa $(\%)$ & Eficiência $(\%)$ & Volume de cinza $\left(\mathrm{m}^{3}\right)$ \\
\hline 52 & 72,8 & 0,375 \\
40 & 77,6 & 0,312 \\
30 & 82,4 & 0,213 \\
25 & 89,1 & 0,187 \\
\hline
\end{tabular}

\section{Discussão}

Os poluentes emitidos pelas caldeiras dependem, fundamentalmente, do tipo de combustível que é utilizado, principalmente no que diz respeito à umidade da biomassa, combustão completa, das características construtivas das caldeiras, das condições de operação e da manutenção dos equipamentos. Para Francisco (2012) e Ferreira (2016) o teor de umidade é um fator de estrema importância para o processo de combustão. Sendo que, segundo Ferreira et al. (2016) devido ao processo de variação da umidade do Pinus sp. é necessário a estocagem e acompanhamento do teor de umidade para uma maior viabilidade do poder calorífico líquido nas caldeiras. Garstang et al. (2002), Jirjis (2005) e Brand et al. (2014b) descrevem que a realização da estocagem da biomassa auxilia na diminuição do Teor de umidade da biomassa. Obtendo um tempo de estocagem ideal de 4 meses para Pinus sp. e Eucalyptus sp., sendo que o Pinus sp. é menos heterogêneo no teor de umidade que o Eucalyptus sp. (Brand et al., 2014b).

A caldeira que utiliza biomassa como combustível faz com que todo o seu produto e seu resíduo tenham o melhor aproveitamento no ponto de vista ambiental. Simioni e Hoeflich (2009) descrevem que embora a utilização de resíduos das atividades florestais (cavaco) na forma biomassa para produção de energética é viável, no entanto, é preciso uma atenção das empresas com esse material, visto que o tratamento inadequado desses resíduos é um processo que limita o seu aproveitamento energético.

Segundo Simioni e Hoeflich (2010) a geração de energia através da biomassa de origem florestal demonstra um crescimento em alguns municípios de Santa Catarina. Para Moreira (2012) o processo pela busca de energia é constante, buscando atender a demanda por diferentes usos, porém é preciso desenvolver um monitoramento contínuo no processo de emissão de gases na Campos, R.F.F.; Rosa, L.D.; Tiago, B. atmosfera. Conforme a Indústria Brasileira de Árvores - IBA (2015) em 2014 as atividades florestais no Brasil apresentaram uma geração de 33,60 milhos de resíduos e desses apenas 8,8 milhões, compondo $65,8 \%$ foram destinados ao processo de geração de energia por meio da queima em caldeiras que geram vapor.

A principal preocupação de emissão de fontes que utilizam madeira (cavaco na forma de biomassa) como combustível em relação ao meio ambiente são os materiais particulados e outros gases decorrentes da combustão incompleta, conforme legislação especifica são empregado os valores limitantes a um índice que se considere dentro dos parâmetros aceitáveis. Essas emissões dependem principalmente da composição do derivado de madeira utilizado como combustível e do equipamento de controle de emissões.

Podermos observar no estudo uma redução da emissão de dióxido de carbono e monóxido de carbono conforme a diminuição do teor de umidade na biomassa, sendo que a biomassa com umidade de $52 \%$ obteve uma geração média de 14,63 ppm $\left(\mathrm{CO}_{2}\right)$ e $785,54 \mathrm{ppm}(\mathrm{CO})$ e a biomassa com umidade $25 \%$ obteve uma geração média de 9,29 ppm $\left(\mathrm{CO}_{2}\right)$ e 388,31 ppm (CO), conforme Tabela 1 e 2. Portanto, quanto menor a taxa de umidade da biomassa maior é a eficiências da queima e por consequência menor geração de $\mathrm{CO}_{2}$ e $\mathrm{CO}$. Segundo Calegari et al. (2005) a umidade influência no poder calorífico da biomassa.

Conforme analise da emissão de oxigênio em diferentes tipos de umidade podemos observar atreves da Tabela 3., que quando há uma diminuição da umidade da biomassa no processo de combustão, consequentemente aumenta à emissão de oxigênio, sendo que a biomassa de $52 \%$ obteve uma média de $5,97 \%$, $40 \%$ obteve uma média de $7,30 \%, 30 \%$ obteve uma média de $10,22 \%$ e $25 \%$ de umidade obteve uma média de $11,31 \%$ de oxigênio lançado na atmosfera. Essa questão está atribuída ao processo de combustão, na etapa exotérmica, sendo que, quanto maior a 
quantidade de umidade $\left(\mathrm{H}_{2} \mathrm{O}\right)$ maior será a necessidade de oxigênio para combustão completa da biomassa, que representa $70 \%$ do poder calorífico da biomassa. Segundo Francisco (2012) em um estudo de análise da queima de carvão em caldeiras em uma caldeira apresenta, que conforme o aumento da umidade menor é a eficiência da queima, como também aumenta o processo de emissão de gases de exaustão. Apresentando as mesmas características que o presente estudo.

$O$ estudo apresenta uma redução na geração de cinzas, conforme a diminuição do TUC, visto que a biomassa com $52 \%$ de umidade apresentou uma geração de $0,375 \mathrm{~m}^{3} \mathrm{e}$ a biomassa com umidade de $25 \%$ apresentou uma geração de $0,187 \mathrm{~m}^{3}$, obtendo um diminuição de $0,188 \mathrm{~m}^{3}$. Essa questão está atribuída ao processo de eficiência energética da biomassa, onde uma menor concentração de umidade, maior será a queima e consequentemente uma menor geração de resíduos. Segundo Gimenes (2012) quanto maior o teor de umidade da biomassa, maior será seu tempo de permanência na caldeira, visto que a umidade influencia na combustão, onde mais umidade maior é o tempo de evaporação (há uma forte influência negativa da umidade do cavaco na temperatura da chama), consequentemente maior a queima incompleta, obtendo mais geração de cinzas.

Segundo Maeda et al. (2007) é preciso buscar alternativas sustentáveis para a destinação correta da cinza de caldeira. Para Gonzalez (2014) as cinzas geradas no processo de combustão apresentam nutrientes na forma solúvel, tornando os nutrientes menos suscetíveis à lixiviação. Cacuro e Waldman (2015) descrevem que devido a heterogeneidade das cinzas é preciso desenvolver estudos mais concretos sobre a cinza gerada e qual sua interação com solo e produção florestal. De acordo com Maeda et al. (2007) a utilização de cinza de caldeira proveniente da combustão da biomassa florestal e um experimento em casa de vegetação, não apresentou nenhum tipo de contaminação no solo e água de percolação.

A umidade da biomassa também apresenta interação com o processo de eficiência energética, visto que a biomassa com $25 \%$ umidade apresenta uma média de $89,10 \%$ de eficiência e a biomassa com $52 \%$ de umidade apresenta uma média $72,85 \%$ de eficiência de queima. Segundo Quirino et al. (2005) a eficiência da combustão está associado com as características química da biomassa, onde a lignina e extrativos como resinas, óleos-resínas, matérias graxas e óleos proporcionam seu potencial. Para Nascimento et al. (2006) o Poder Calorífico Superior - PCS é o processo realizado na combustão para diminuir a umidade da biomassa e proporcionar a combustão do material seco, visto que essa energia gasta depende da umidade, estando relacionada com a eficiência energética. Conforme Furtado et al. (2012) existe uma relação negativa entre o teor de umidade da biomassa quando submetido a geração de energia.

As emissões que foram medidas na caldeira da empresa Adami S/A estão todas dentro dos parâmetros legais, no entanto, deve-se tentar reduzir ao máximo a quantidade de monóxido de carbono emitido. Segundo Moreira (2012) para melhor a eficiência das caldeiras e controle da emissão de poluentes, é preciso implantar um sistema efetivo de combustão. Sabendo disso, é necessário buscar soluções para reduzir a umidade deste material, além de trabalhar com a quantidade de ar adequada para uma queima mais completa possível, através de análises de 10 a $20 \%$ de umidade na biomassa de Pinus $s p$.

Ambientalmente essas medições devem se tornar permanente e passível de ajustes no processo, sempre que, algum parâmetro indique que se inicia uma contaminação mais elevada, bem como novos testes e medições nesse sentido auxiliarão nas tomadas de decisões para que se possa interferir positivamente nos processos, a fim de buscar parâmetros que atendam a legislação ambiental e as necessidades da empresa. Para Moreira (2012) o processo de identificar, analisar e comparar a emissão dos gases gerados em uma caldeira de força apresenta benefícios nas condições ambientais, econômicas, operacionais, técnicas e de qualidade. Visto que, esse processo gera confiança e credibilidade, devido ao menor impacto gerado, como também pela contribuição para a minimização do aquecimento global e consequentemente preserva à cama de ozônio.

Dentre tudo isso, o processo produtivo da empresa do estudo deve atender tudo que esteja abrangendo as questões ambientais econômicas e sociais, almejado a diminuição dos impactos ambientais, através de analises complementares de composto de azoto $\left(\mathrm{NO}_{\mathrm{X}}, \mathrm{NO}, \mathrm{NO}_{2}\right.$ e $\left.\mathrm{N}_{2} \mathrm{O}\right)$, gases ácidos (HCL), óxidos de enxofre $\left(\mathrm{SO}_{2}\right)$, metais pesados $(\mathrm{Pb}, \mathrm{Zn}, \mathrm{Cd})$ e outros que interajam de forma negativa com o meio ambiente.

\section{Conclusões}

Neste contexto, após a análise de combustão da biomassa sob diferentes umidades, pode-se concluir que a umidade da biomassa de Pinus sp. influência no processo de emissão de $\mathrm{CO}_{2}, \mathrm{CO}$ e $\mathrm{O}_{2}$, como também na eficiência da combustão e consequentemente na geração de resíduos sólidos (cinzas), devido a combustão completa com menor umidade estabelecida. 
Os dados obtidos durante o período de medição poderá ser usado como referencia para a empresa do estudo, auxiliando as tomadas de decisão estratégica em investimentos financeiros por parte da empresa em novas tecnologias para controle de queima ideal da biomassa.

Assim, o estudo visa o desenvolvimento de novos testes nesse segmento, como também a medição continua desses gases a fim de confrontar os resultados e até mesmo confirmar o valor ideal de umidade, e dessa forma poder tomar decisões assertivas a respeito.

\section{Agradecimentos}

Á empresa Adami S/A pela disponibilização da área do estudo e a Universidade Alto Vale do Rio do Peixe pelo suporte na realização do referido trabalho.

\section{Referências}

ABNT. Associação Brasileira de Normas Técnicas, 2003. NBR 14929: Madeira - Determinação do teor de umidade de cavacos - Método por secagem em estufa. Rio de Janeiro.

Angelis-Dimakis, A.; Biberacher, M.; Dominguez, J.; Fiorese, G.; Gadocha, S.; Gnansounou, E.; Guariso, G.; Kartalidis, A.; Panichelli, L.; Pinedo, I.; Robba, M. (2011) Methods and tools to evaluate the availability of renewable energy sources. Renewable Sustainable Energy Reviews 15, 1182 - 1200.

Arbex, M.A.; Cançador, J.E.D.; Pereira, L.A.A.; Braga, A.L.F.; Saldiva, P.H.N. (2004) Queima de biomassa e efeitos sobre a saúde. Jornal Brasileiro de Pneumologia 30, 158-175.

Bareta, A.; Guzzo, P.; Oliveira, J.; Aragão, V.; Nadal, R. (2005) Desenvolvimento de um modulo de picagem de ponteira de eucalipto para utilização como biomassa pela Jari Celulose. Biomassa \& Energia 2, 331-340.

Blasi, C. D. (2006) Modeling chemical and physical processes of wood and biomass pyrolysis. Elsevier: Progress in energy and combustion science 7, 47-90.

Brasil, 2011. Resolução Conama ${ }^{\circ}$ 436, de 22 de dezembro.

Braga, B.; Hespanhol, I.; Conejo, J.G.L.; Mierzwa, J.C.; Barros, M.T.L.; Spencer, M,; Porto, M., Nucci, N.; Juliano, N.; Eiger, S. (2005) Introdução à engenharia ambiental: $\mathrm{O}$ desafio do desenvolvimento sustentável. 2. ed. São Paulo: Pearson Prentice Hall, 2005.

Brand, M.A.; Muniz, G.I.B.; Brito, J.O.; Quirino, W.F. (2014a) Influência das dimensões da biomassa estocada de Pinus taeda L. e Eucalyptus dunnii Maiden na qualidade do combustível para geração de energia. Rev. Árvore 38,175-183.

Brand, M.A.; Stahelin, T.S.F.; Ferreira, J.C.; Neves, M.D. (2014b) Produção de biomassa para geração de energia em povoamentos de Pinus taeda L. com diferentes idades. Rev. Árvore 38, 353-360.

Bizzo, W. A. Geradores De Vapor. EM 722 Geração, Distribuição e Utilização de Vapor. Unicamp. (2004). Disponível em: <http://www.fem.unicamp.br/ em672/GERVA P4.pdf> Acesso em: Agosto, 2016.

Cacuro, T.A.; Waldman, W.R. (2015) Cinzas da Queima de Biomassa: Aplicações e Potencialidades. Rev. Virtual Quim. 7, 21542165.

Calegari, L.; Foelkel, B.C.E.; Haselein, C.R.; Andrade, J.L.S.; Silveira, P.; Santini, E.J. (2005) Caracteristicas de algumas biomassas usadas na geração de energia no sul do Brasil. Biomassa \& Energia 2, 37-46.

CTESB. Companhia Ambiental Do Estado De São Paulo (2015) Plano de redução de emissão de fontes estacionárias - Fontes de combustão. Disponível: http://ar.cetesb.sp.gov.br/wpcontent/uploads/sites/37/2015/12/Guia-MTPDFontes-de-Combust\%C3\%A3o.pdf. Acesso: 25 Jan. 2017.

EMBRAPA. Empresa Brasileira de Pesquisa Agropecuária, 2007. Cinza de Biomassa Florestal como Insumo para Plantio de Pinus taeda em Cambissolo e Latossolo em Vargem Bonita, SC. Comunicado Técnico 187: Colombo.

Ferreira, J.C.; Stähelin, T.S.F.; Valin, M.; Brand, M.A.; Muñiz, G.I.B. (2016) Qualificação da biomassa em povoamentos florestais de Pinus taeda. FLORESTA 46, $269-276$.

Francisco, R.P. (2012) Estudo termoquímico da queima de combustíveis em caldeira usando balanço de energia. Dissertação (Mestrado). Minas Gerais. UFSJ.

Freitas, E.S. (2005) Estudo da eficiência e da emissão de caldeira operada a diesel e biodiesel. Dissertação (Mestrado). Rio de Janeiro, UFRJ.

Furtado, T.S.; Ferreira, J.C.; Brand, M.A.; Neves, M.D. (2012) Correlação entre teor de umidade e eficiência energética de resíduos de Pinus taeda em diferentes idades. Rev. Árvore 36, 577-582.

Garstang, J.; Weekes, A.; Poulter, R.; Bartlett, D. (2002) Identification and characterisation of factors affecting losses in the large-scale, nonventilated bulkstorage of wood chips and development of best storage practices. Publication 02/1535, London: Department of Trate and Industry. 
Gimenes, J. (2012) Análise da geração, recuperação e destinação de cinzas em caldeira - O caso de uma indústria. Tese (Especialização). Curitiba. UFPR.

Gonzalez, A.D. (2014) Caracterização e análise comparativa de cinzas provenientes da queima de biomassa. Tese (Mestrado). São Paulo, UNICAMP.

IBA. Indústria Brasileira de Árvores (2015) Indicadores Socioambientais. Disponivel: http://iba.org/images/shared/iba_2015.pdf. Acesso: 25 Jan. 2017.

Jirjis, R. (2005) Effects of particle size and pile height on storage and fuel quality of comminuted Salix viminalis. Biomass and Bioenergy, 28, 193-201.

Mano, E.B.; Pacheco, E.B.A.V.; Bonelli, C.M.C. (2010) Meio Ambiente, Poluição e Reciclagem. $2^{a}$ ed. São Paulo: Blucher.

Moreira, L.C.O. (2012) Comparação entre os poluentes atmosféricos emitidos por uma caldeira flamotubular movida a gás natural e a óleo combustível BPF $2^{\mathrm{a}}$. INTERAÇÕES 13, 49-57.

Nascimento, S.M.; Dutra, R.I.J.P.; Numazawa, S. (2006) Resíduos de indústria madeireira: caracterização, consequências sobre o meio ambiente e opções de uso. HOLOS Environment, 6, 8-21

Offermann, R.; Seidenberger, T.; Thran, D.; Kaltschmitt, M.; Zinoviev, S.; Miertus, S. (2011) Assessment of global bioenergy potentials. Mitigation and Adaptation Strategies for Global Change 16, 103-115.

Oliveira, J.LF. (1997) Poluição atmosférica e o transporte rodoviário: perspectivas de uso do gás natural na frota de ônibus urbanos da cidade do rio de janeiro. Tese (Mestrado). Rio de Janeiro, UFRJ.
Padilha, J.L.; Rendeiro, G.; Brasil, A.C.M.; Santos, R.E.J.; Pinheiro, G. (2005) Potencial de geração de energia elétrica no estado do Pará, utilizando a biomassa do setor madeireiro. Biomassa \& Energia 2, 267-284.

Quirino, W.F.; Vale, A.T.; Andrade, A.P.A.; Abreu, V.L.S.; Azevedo, A.C.S. (2005) Poder calorífico da madeira e de materiais lignocelulósicos. Revista da Madeira 89, 100 - 106.

Salum, A.D. (2011) Eficiência energética em sistema de combustão de caldeira. Monografia (Especialização). Salvador, UFBA.

Sales, C.A.V.B.; Andrade, R.V.; Lora, E.E.S. (2005) Geração de energia elétrica a partir da gaseificação de biomassa. Biomassa \& Energia 2, 195-204.

Silva, F.A.S.; Azevedo, C.A.V., 2009. Principal components analysis in the software assistat statistical attendance. In: World congress on computers in agriculture, 7, Reno-NV_USA: America Social Agriculture Biology Engineer.

Simioni, F.J.; Hoeflich, V.A. (2009) Cadeia produtiva de biomassa de origem florestal no planalto sul de Santa Catarina. FLORESTA 39, 501-510.

Simioni, F.J.; Hoeflich, V.A. (2010) Cadeia produtiva de energia de biomassa na região do planalto sul de Santa Catarina: Uma abordagem prospectiva. Revista Árvore, 34, 1091-1099.

Wander, P.R. (2001) Utilização de resíduo de madeira e lenha como alternativas de energias renováveis para o desenvolvimento sustentável da região nordeste do estado do Rio Grande do Sul. Tese (Doutorado). Porto Alegre, UFRS. 